\title{
A MORALIDADE PRESENTE NOS SITES DE REDES SOCIAIS
}

Aline Kadooka, Rita Melissa Lepre, Vítor de Morais Alves Evangelista.

Universidade Estadual Paulista - UNESP, Programa de Pós-Graduação em Psicologia, Câmpus de Assis, SP. E-mail: alinekadooka@gmail.com

CAPES - Coordenação de Aperfeiçoamento de Pessoal de Nível Superior

\section{Resumo}

O uso de equipamentos digitais e o acesso à rede mundial de computadores têm contribuído para ampliar a complexidade das relações sociais. Se por um lado, as redes sociais tem facilitado a vida dos indivíduos, por outro, vários riscos e problemas assolam os seus usuários. Alguns usuários da rede sentem-se mais à vontade para executar ações virtuais, por vezes despercebidas, que acabam por perpetrar o assédio através das redes. A falta de uma moral que oriente os sujeitos acaba por ser a principal responsável pela origem desses problemas. Essa nova realidade de relações interpessoais, explicitadas pelas inúmeras formas de interação virtual, trazem para o horizonte novos desafios contemporâneos que devem ser compreendidos e analisados. Cabe, portanto, a nós pesquisadores acompanhar o desenvolvimento dessas novas formas de ser no mundo, trazendo à roda debates fecundos para o desenvolvimento de novas abordagens sobre o tema.

Palavras-chave: Moralidade, Sites de Redes Sociais, WEB, Comunicação, Cyberbullying.

\section{MORALITY IN THIS SOCIAL NETWORKING SITES}

\begin{abstract}
The use of digital equipment and access to the World Wide Web have contributed to increase the complexity of social relations. On the one hand, social networks have facilitated the lives of individuals, on the other, a number of risks and problems plaguing its users. Some network users feel more comfortable to run virtual actions, sometimes unnoticed, you end up perpetrating harassment across networks. The lack of a moral guiding the subject turns out to be primarily responsible for the origin of these problems. This new reality of interpersonal relations, explained the numerous forms of virtual interaction, bring to the horizon new contemporary challenges that must be understood and analyzed. It is therefore up to us researchers to follow the development of these new ways of being in the world, bringing the wheel fruitful discussions for the development of new approaches to the topic.
\end{abstract}

Keywords: Morality, Social Networking Sites, Web, Communication, Cyberbullying. 


\section{INTRODUÇÃO}

A informatização tornou-se marca registrada do mundo contemporâneo, mas será que estamos realmente conscientes das consequências de toda essa evolução? Os avanços das ciências e da tecnologia fizeram emergir novas formas de comunicação que influenciaram em diversos aspectos do mundo real e produziram inúmeros efeitos nos sujeitos. A sofisticação dos meios de comunicação e a massificação do uso da Internet na chamada "sociedade em rede" estão proporcionando grandes mudanças em diferentes âmbitos da sociedade contemporânea. Por isso a investigação sobre o uso das redes tornou-se essencial para pensar sobre as suas repercussões na humanidade, mais precisamente por causa dos impactos imprevisíveis das tecnologias na política econômica, cultural, de trabalho e de lazer de nossas sociedades (CABRATORRES E MARCIALES-VIVAS, 2011).

A comunicação além de ser essencial para o exercício da cidadania é uma das responsáveis pelo molde da cultura (CASTELLS, 1999). Ao mesmo tempo, os meios de comunicações foram afetados drasticamente pela evolução tecnológica, de modo que, não apenas alterou os hábitos cotidianos, mas instaurou uma nova forma viver, o "viver online". Essa nova configuração cultural é marcada pela possibilidade de aparentar ser alguém, qualquer alguém que a imaginação desejar (COLVARA, 2013).

Para AVILÉS (2010, 2015, 2013a, 2013b), se por um lado, as redes sociais tem facilitado a comunicação entre os indivíduos, superado a barreira da distância e do tempo e aumentado a nossa rede de contatos, trazendo assim, melhorias na aprendizagem, troca de informações, amizades, por outro, vários riscos e problemas assolam os seus usuários. $\mathrm{O}$ uso indiscriminado e descontrolado da rede tem contribuído para o surgimento de: dependência, vícios, hiperconexão, hipervirtualidade, distância emocional, imediatismo-impulsividade, agressividade, diminuição do desempenho escolar, cyberbullying, entre outros. Além disso, também tem contribuído para o agravamento e crescimento exponencial de velhos problemas que tradicionalmente eram desenvolvidos somente através da interação face-a-face (Ex.: Violências e Violências Virtuais; Bullying e Cyberbullying;). Alguns usuários da rede, encobertos pela sensação de proteção advinda do estar em ambiente virtual, sentem-se mais à vontade para expressar as suas opiniões e sentimentos ou executar ações, por vezes despercebidas, que acabam por perpetrar o assédio através das redes. Estas formas de assédio tomaram várias formas: desrespeito (enviando mensagens e/ou divulga publicações ofensivas ou vulgares), perseguição (envio de mensagens ameaçadoras), difamação (espalhando rumores), violação de privacidade (divulgação de segredo ou imagens), exclusão social (exclusão deliberada de pessoas ou grupos na rede), representação (envio de mensagens maliciosas passando se por outra pessoa). Tais condutas seriam uma manifestação de uma falta de moral que oriente os agentes de tais ações.

\section{A WEB E OS SITES DE REDES SOCIAIS}

A Web foi inventada a partir de pesquisas militares no final da década de 90 , tendo como principal contexto a Guerra Fria. Sua primeira versão tinha como objetivo principal a comunicação e a transmissão de dados. Passou então a ser uma rede que interligava universidades ao redor do mundo. A sua popularização se deu gradativamente com o barateamento dos custos de acesso comercial à rede. Essa propagação foi o que permitiu o surgimento de enciclopédias abertas, ferramentas de comunicação em diferentes formatos e o comércio eletrônico (COLVARA, 2013). Posteriormente, ela foi sendo aperfeiçoada e ganhou o status de Web 2.0, essa denominação foi cunhada, após receber significativas mudanças em sua utilidade, migrando de um simples canal de consulta e comunicação para uma plataforma interativa. Podemos destacar nessa transição o aparecimento dos chamados Sites de Redes Sociais Online (SRS), que são sistemas que permitem a interação de pessoas, a formação de grupos e diversas formas de compartilhamento de informações (DE SANTANA ET AL, 2009). Ellison et al. (2007) definem as SRSs como espaços 
utilizados para expressão na Internet. Eles são diferenciados dos sites da Web por permitirem ao usuário a construção de um perfil (persona) ou página social, interações através dos comentários e a exposição pública de cada ator. De acordo com, Machado e Tijiboy (2005) esses sites ou softwares sociais funcionam como mediadores sociais, já que permitem que os usuários se relacionem com outras pessoas no ambiente virtual, além de proporcionar a experiência de partilha, o aglutinamento de pessoas através de interesses comuns e a discussão de vários temas. Esses sites se multiplicam a cada dia na WEB, em contínuo movimento de mudança, cada um com objetivos e recursos específicos, mas no geral, as redes de relacionamentos virtuais visam impulsionar as relações humanas, oferecendo ao outro a oportunidade de observarem através de suas publicações, um pouco do seu cotidiano. Essa sofisticação dos meios de comunicação, não alterou apenas os hábitos cotidianos, mas criou uma nova ideia de espaço. O espaço cibernético ou ciberespaço nada mais é que um espaço virtual. Para Pierre Levy (2010) o virtual seria à ausência de existência, ou seja, aquilo que está na ordem das ilusões, do imaginário. Se focalizarmos essa teoria nas relações entre as pessoas, a relação virtual seria aquela do não encontro, baseadas nas fantasias dos sujeitos.

\section{MORALIDADE E REDES SOCIAIS}

Os estudos sobre a moralidade remontam à antiguidade. Filósofos buscavam discutir sobre os conceitos atrelados ao bem e ao mal. Porém, é na modernidade, influenciado pelo lluminismo e pela racionalidade emergente, que o filósofo alemão Immanuel Kant, introduz as suas ideias sobre a moralidade. Para ele a moral não era a simples adesão às regras determinadas pela sociedade, 0 agir moralmente "bom ou certo" deveria obedecer ao princípio incondicional e universal chamado de Imperativo Categórico: "age apenas segundo uma máxima tal que possa querer que ela se torne lei universal" (KANT, 1964, p. 223). Além dessa discussão, Kant teorizou sobre a existência de duas grandes tendências morais: a heteronomia, que significa ser governado por outros sem questionamento às regras impostas, pelo medo à punição ou visando o bem estar e o interesse próprio; e a autonomia, que requer uma descentralização, de forma que, fundamentando-se no Imperativo Categórico, o sujeito seja capaz de se colocar no lugar do outro para agir moralmente de acordo com o bem (MENIN, 1999).

Para Émile Durkheim (1970) a moral é um sistema de regras de conduta inseparáveis dos indivíduos em sociedade, que são formadas a partir de um conjunto de crenças e sentimentos comuns à coletividade e passadas através das gerações. Para ele toda corporação, seja ela, família, cidade ou pátria; dependerá de regras morais que possibilitarão a convivência em sociedade; ela é, portanto, fruto de uma consciência coletiva em detrimento das individuais. Ao passo que, todos os atos que forem contra a esse sistema de regras serão identificados como atos imorais. Todavia, para se distinguir as regras morais de outras regras, Durkheim ressalta duas características: primordialmente as regras morais são atreladas à obrigação (noção do dever) e, em segundo lugar, o seu cumprimento não se deve dar meramente como uma resposta a uma ordem, mas deve ter algum significado ou finalidade para o autor que a executa. Também, o autor assinala que a moral acompanha o contexto social da época, e por isso, não é imutável e nem inextinguível, ela sempre sofrerá ajustes conforme a consciência pública que passa a negá-la, mantê-la ou modifica-la pela força das tradições.

Para Zingano (2013), quando nos dispomos a pensar no caráter bom ou mau de algo estamos envolvidos com avaliações de cunho tipicamente moral. Mas também, ao julgarmos algo como certo ou errado estamos lidando com avaliações morais. O mesmo ocorre quando caracterizamos um ato ou uma emoção como corretos ou incorretos. Ele pontua ainda que a linguagem moral tem como objetivo formular os imperativos que exprimem ações que devem ser executadas ou não. 
Tognetta e Bozza (2012) aplicaram um questionário em 63 adolescentes de 14 anos, estudantes de colégios públicos de Campinas-SP para investigar se existia ou não uma possível correspondência entre as representações que os sujeitos têm de si e a prática Cyberbullying através do site de relacionamento "Orkut". As autoras encontraram uma correspondência entre os não praticantes de Cyberbullying e aqueles adolescentes cujas representações de si baseavam as sua ações em conteúdos éticos e admiravam os valores morais, tais como a justiça e a generosidade e eram capazes refletir e incluir os outros em suas ações.

Tognetta e Rosário (2013) realizaram um estudo que tinha como objetivo investigar se os engajamentos ou desengajamentos morais possuíam relação com a prática de bullyng. Como resultado, eles encontraram que os indivíduos que praticavam o bullying eram mais desengajados ou menos engajados às situações morais. Isso demonstrou que os autores de bullying conseguiam desativar seletivamente o controle de um mau comportamento moral, justificando-a moralmente. Esse desengajamento moral serviria como um desinibidor de condutas moralmente incorretas que libertariam o autor da culpa e da autocensura. Essas mesmas autoras demonstraram através do levantamento bibliográfico, que a presença de desengajamentos morais dificultaria que o sujeito se colocasse no lugar do outro ou se comovesse com a sua dor. E, mais ainda, as emoções ligadas ao desengajamento moral seria o orgulho e a indiferença, enquanto as associadas à responsabilidade moral seriam a culpa e a vergonha. Outro fato levantado por esses autores é que os sujeitos que praticam o cyberbullying apresentam ainda maior desengajamento moral do que aqueles que praticam o bullying de maneira tradicional.

Rocha (2010) realizou uma pesquisa cujo objetivo era analisar o processo de produção discursiva e as práticas de cyberbullying dirigidas a professores em um site de redes sociais, o Orkut. A pesquisadora adotou como metodologia a Etnografia Virtual com observações participantes mediadas por computador e a aplicação de um questionário online. Na primeira etapa da pesquisa a autora adentrou o mundo do Orkut, explorando todas as ferramentas da plataforma, principalmente aquela denominada de comunidades virtuais, tais como: "Eu odeio o professor George" e "Professores sofredores". Na segunda etapa, foi aplicado um questionário online com 14 questões objetivas, dentre estas, além das relativas ao perfil sociodemográfico, os professores puderam relatar diferentes tipos de situações de violência que sofreram, ou o próprio cyberbullying no Orkut, no total foram 82 respondentes. A autora destaca o papel fundamental e a importância da etnografia para o estudo, pois Ihe foi permitido, tanto analisar e refletir sobre os atos e justificativas dos alunos perpetradores, quanto dos professores que eram as vítimas. Como resultado, a pesquisadora encontrou que neste contexto de violência, foi identificado que embora os alunos exprimam opiniões importantes sobre os seus professores, também acabam por banalizar e naturalizar o ódio e a violência nas redes sociais. Esse sentimento de liberdade por parte dos alunos é encorajado pelo sentimento de diluição das hierarquias na internet, o poder de participação, o direito de se expressar como quiser e a comunicação horizontalizada. A autora cita que muitas vezes a violência é gerada a partir de um autoritarismo pedagógico, como resposta à repressão imposta pelos professores através de práticas pedagógicas abusivas ou repressivas. Por parte dos professores, foi possível verificar que ao se sentirem desautorizados, desrespeitados ou impotentes diante da indisciplina ou da atitude rebelde do aluno, os mesmos revidam através da violência psicológica contra o aluno. Eles sentem-se fragilizados, impotentes, e impedidos de exercer sua função de educador. Desmotivados, tanto pelas questões de relacionamento com os alunos, quanto pela baixa remuneração, reconhecimento e péssimas condições de trabalho; o educador é preenchido por sentimentos de desqualificação, estresse, desilusão, baixa autoestima. Sob essas condições acabam inevitavelmente se desgastando (Burnout), sendo justificáveis as licenças médicas, o afastamento temporário, e muitas vezes, definitivo.

A ideia de que crianças e adolescentes enfrentam uma série de riscos na Internet, tornouse um tema frequente de pesquisas em psicologia, educação, etc (CABRA-TORRES E MARCIALES- 
VIVAS, 2011). Cabra-Torres e Marciales-Vivas (2011) ressaltam a preocupação e o medo dos pais no cuidado com os seus filhos em relação às mudanças dos meios de comunicação, especialmente a Internet, pois o seu uso é de difícil controle e tem facilitado o acesso a todo tipo de conteúdo para crianças de todas as classes sociais e idades.

\section{CONSIDERAÇÕES}

Esse artigo buscou retratar brevemente um panorama sobre a influência da moralidade nos usuários dos SRS. Ora, pensando na questão moral, será que existe algum limite nas redes? Ou tudo é permitido por não ser real ou estar no virtual?

É cada vez mais comum escutarmos frases que denotam a falta de educação da geração atual em comparação à anterior. Por exemplo: "No meu tempo, bastava o olhar de meu pai... bastava o olhar da professora para que uma regra fosse cumprida" (TOGNETTA; VINHA, 2009, p.15). Essas autoras, por meio de uma pesquisa de campo com jovens entre 14 e 16 anos, investigaram quais seriam, atualmente, os valores almejados pelos jovens e quais atitudes de outrem que os deixavam indignados. Resumidamente, os resultados dessa pesquisa demonstraram que de fato ainda há valores morais nos jovens, no entanto, parece que o conteúdo dos valores está se modificando, de morais, por valores estranhos ou até contrários à moralidade. Prevalece nesses adolescentes um senso de justiça individualista ou no máximo estendido às suas relações afetivas, já que $76 \%$ dos participantes disseram que não generalizariam os valores para qualquer ser humano. Isso nos demonstra que a geração atual, reflete de maneira heterônoma e restringem a moral à esfera privada em detrimento da dimensão pública.

Essa nova realidade de relações interpessoais, explicitadas pelas inúmeras formas de interação virtual, trazem para o horizonte novos desafios contemporâneos que devem ser compreendidos e analisados. Cabe, portanto, a nós pesquisadores acompanhar o desenvolvimento dessas novas formas de ser no mundo, trazendo à roda debates fecundos para o desenvolvimento de novas abordagens sobre o tema.

\section{REFERÊNCIAS}

CABRA-TORRES, F.; MARCIALES-VIVAS, G. Internet y pánico moral: revisión de la investigación sobre la interacción de niños y jóvenes con los nuevos medios. Universitas Psychologica, v. 10, n. 3, p. 855-865, 2011.

AVILÉS, José María Avilés Martínez. Éxito escolar y ciberbullying. Boletín de psicología, n. 98, p. 7385, 2010.

. José María Avilés Martínez. Análisis psicosocial del ciberbullying: claves para una educación moral. Papeles del psicólogo, v. 34, n. 1, p. 65-73, $2013 a$.

. José María Avilés Martínez. Programa educativo PRIRES: Programa de Prevención de Riesgos en las Redes Sociales. Revista de Investigación en Psicología, v. 17, n. 2, p. 13-23, 2015. . José María Avilés Martínez. A PSYCHOSOCIAL ANALYSIS OF CYBERBULLYING: KEYS TO A MORAL EDUCATION. Papeles del Psicólogo, v. 34, n. 1, p. 65-73, 2013b.

CASTELLS, Manuel; EM REDE, A. Sociedade. A era da informação: economia, sociedade e cultura. São Paulo: Paz e Terra, v. 3, 1999. 
COLVARA, Lauren Ferreira. Tecnototemismo: a subjetividade em tempos tecnológicos. 2013. Tese (Doutorado em Psicologia Social) - Instituto de Psicologia, Universidade de São Paulo, São Paulo, 2013.

DE SANTANA, Vagner Figuerêdo et al. Redes sociais online: desafios e possibilidades para o contexto brasileiro. Semish, 2009.

DURKHEIM, Émile. Determinação do fato moral. DURKHEIM, Émile. Sociologia e Filosofia. Rio de Janeiro e São Paulo: Forense, 1970.

ELLISON, Nicole B. et al. Social network sites: Definition, history, and scholarship. Journal of Computer-Mediated Communication, v. 13, n. 1, p. 210-230, 2007.

https://doi.org/10.1111/j.1083-6101.2007.00393.x

KANT, Immanuel. Fundamentação da metafísica dos costumes. São Paulo: Companhia Editora Nacional, 1964.

MACHADO, Joicemengue Ribeiro; TIJIBOY, Ana Vilma. Redes Sociais Virtuais: um espaço para efetivação da aprendizagem cooperativa. RENOTE, v. 3, n. 1, 2005.

MENIN, Maria Suzana de Stefano. Desenvolvimento Moral: Refletindo com pais e professores. In: Cinco Estudos de Educação Moral. Coleção Psicologia e Educação. 2a ed. Casa do Psicólogo. São Paulo,1999.

PIERRE LEVY. Cibercultura. Editora 34, 2010.

ROCHA, Telma Brito. Scr@ps de ódio no Orkut: cyberbullying, contextos e ressonâncias da violência virtual que atinge o professor. 2010. 200 f. Tese (Doutorado) - Faculdade de Educação, Universidade Federal da Bahia, 2010.

TOGNETTA, Luciene Regina Paulino; BOZZA, Thais Cristina Leite. CYBERBULLYING: UM ESTUDO SOBRE A INCIDÊNCIA DO DESRESPEITO NO CIBERESPAÇO E SUAS RELAÇÕES COM AS REPRESENTAÇÕES QUE ADOLESCENTES TEM DE SI. Nuances: estudos sobre Educação, v. 23, n. 24, p. 162-178, 2012.

TOGNETTA, Luciene Regina Paulino; ROSÁRIO, Pedro. Bullying: dimensões psicológicas no desenvolvimento moral. Estudos em Avaliação Educacional, v. 24, n. 56, p. 106-137, 2013. https://doi.org/10.18222/eae245620132736

TOGNETTA, Luciene Regina Paulino; VINHA, Telma Pileggi. Valores em crise: o que nos causa indignação. Crise de valores ou valores em crise, p. 15-45, 2009.

ZINGANO, Marco. As virtudes morais. São Paulo: Wmf Martins Fontes, 2013. 